\title{
The Instrument to Use Contaminated Water to Save Aqua for Future Generation
}

\author{
Harsh Jindal ${ }^{1}$, Jagdeep Kaur ${ }^{*}$ \\ ${ }^{1}$ Department of Computer Science Engineering, Chandigarh University, Punjab, India ${ }^{1}$ \\ ${ }^{2}$ Department of Physics, Chandigarh University, Punjab, India ${ }^{1^{*}}$
}

\begin{abstract}
Article Info

Volume 8 Issue 2

Page Number : 359-361

Publication Issue :

March-April-2021

\section{Article History}

Accepted : 15 April 2021

Published : 24 April 2021

In this paper we will try to conserve the dirty water or the water that is we are wasting daily in small amount but when gathered can be a big volume. Yes, we will use the aqua guard waste water which generally comes out when the water is purified. We will use that time into useful form. The idea is to design a system in a way such that when the water full of impurity comes out of the aqua guard rather than wasting that water, we can think of reusing it in many forms like a container will be attached to the supply which will have this water. As the container will be full then the water will be given to plants as in small amount through direct supply. As we know that the supply of water to plants is very less so as to accommodate less water, we can use it in other household works like washing clothes and utensils and we can not only use it in household works rather we can try to pure it too in this way not only water will be saved from being finished but also as water is very less on earth only, $3 \%$ we can save it for future generation

Keywords : Purified, Oval shaped, Plants, Pipeline, Valve, Purifying sheets, Apparatus

Abbreviation \& Symbol : L- Litres
\end{abstract}

\section{INTRODUCTION}

The impurity water which we generally say contaminated water we waste it a lot. In terms that as the water from aqua guard impurity pipeline comes out then the water directly goes into the channel where all contamination occurs or is thrown after which that water is wasted. This happens not only in one house but almost every house across the world. So, if we consider not wasting that water and rather collecting that water in containers approx. $6 \mathrm{~L}$ of water will be collected in a single day. So, if we take on a large scale approximately 100 houses it means $600 \mathrm{~L}$ a day such a huge number to think of. This could big such a drastic change in our surroundings if that water is used again. The paper focuses and that area only and has designed an apparatus for that. The impure water which comes out of the pipeline can be used in many ways but we had thought to firstly collect that water in container which is ova shaped and has capacity to store approximately 5-6 L of water above of that container will be a shelf which can attain approximately 4-5 plants which will be watered using the aqua guard dirty water supply. As the water 
needed by them is very less so rest water will be stored in the container and will be connected to the pipeline through which water to the whole house is supplied. That pipelines will be given an extension of container in such a way that the initial supply of water is not disturbed. It will be just an additional joint made to that supply which we release rest approximately $5 \mathrm{~L}$ of water in the supply of water. Not only this many alternates can also be set as $5 \mathrm{~L}$ of water can be used on daily basis for washing clothes for 4 persons per day. In this way a lot of fresh water will be saved. Moreover, we can make that water again drinkable by purifying it as follows: As the container will get full of water, we can purify it by setting different layers of purifying sheets or paper that can be replaced manually by a normal person again and again when required as it will shows the red light when they need to be changed. Otherwise, it will always show green light showing that the water inside is purred and is ready to drink or open the valve for the supply of water in the pipeline depending on the fact what the users will choose at that particular moment as the supply to container is continuous. The idea can also work with the water which contains germs such as our sink water in which we wash our hands that water is approx. of more than $10 \mathrm{~L}$ so that water can also be purified and used for other household work not for drinking. The point now arises is now regarding filter sheets that what type of sheets and materials will be used? The solution to this problem is to we will use the plastic sheet of thin plastic which will have a net like apparatus like as shown in Figure 3. As the quality of purifying depends on which type of material, we use like here we will use net made of material as it is used in making the air conditioning cleaner sheets. In this way the germs will get stick to the sheets and let's say in approximately 1 moth we will get notified that kindly change the sheets of the container. At that moment the sheet will need to be changed and the cost of such type of sheet is very less (cost effective). This means that this apparatus is very to use and affordable to use in every household, industries and everywhere in the world.

\section{METHOD TO BUILD}

- We need to establish an oval shaped container have one slab on the top and two holes on the right and one on back side.

- The holes will be connected with the pipes such that one hole is connected to aqua guard supply and the other on drinking water on right side. The hole on the backside can be connected with the initial pipeline of house from where fresh water is supplied in whole house.

- Setup the whole apparatus near the aqua guard basic requirement.

\section{IMAGES OF STEP OF CONSTRUCTION}

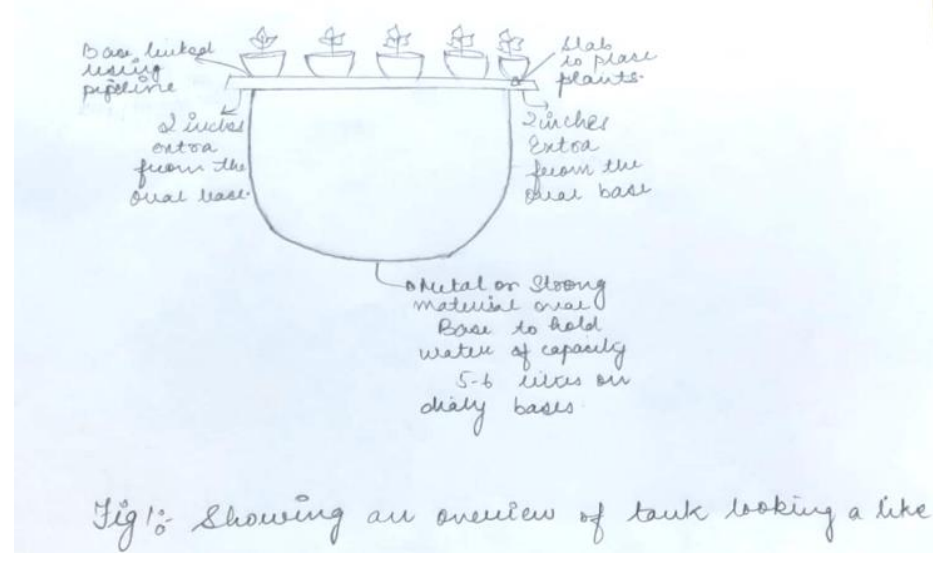

FIGURE 1

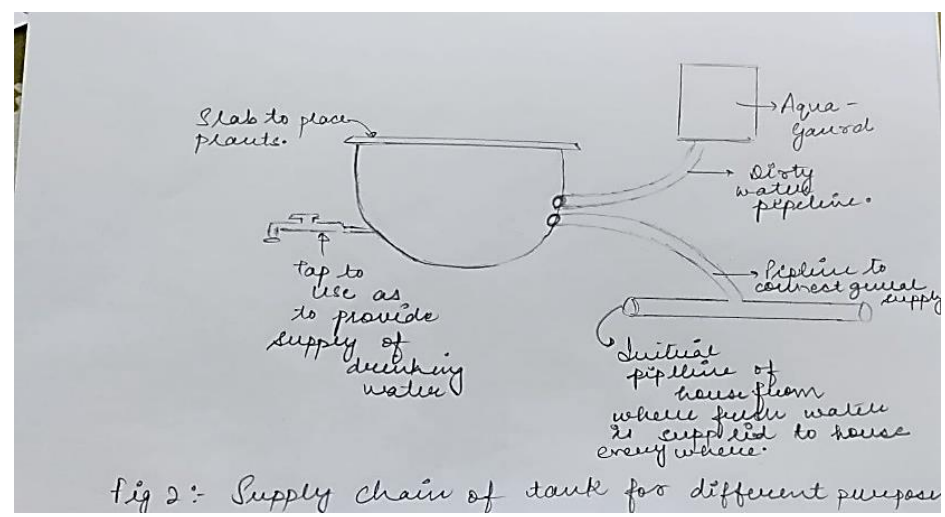

FIGURE 2 


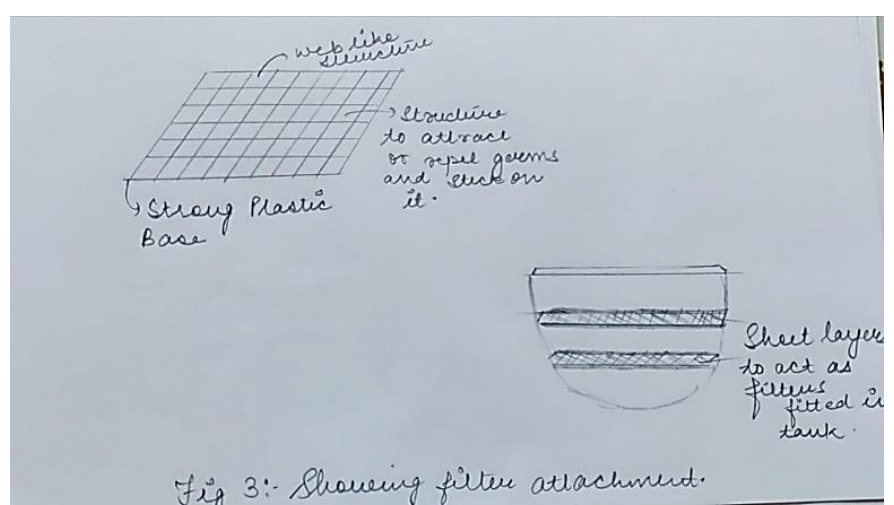

FIGURE 3

III. RESULT

The apparatus or the invention constructed is based on daily requirement and can be used in every household. This will not only save water for our future generation but also it can be used to reduce the loss of water and recycle it.

\section{DISCUSSION}

The point discussing is we have a lot of means to save water we need them all to implied in order to save nature and our future generations. "Think big to act big" is the only need of today's world and even the requirement of today's generation.

\section{CONCLUSION}

Besides giving unrealistic approach the paper focus on the process of how to conserve water and work with the idea if the contaminated water after boiling can be purified that why can't impurely water and with this concept the paper has tried to portray an apparatus that can be used a large scale to save water in all over the world and also it represents full procedure of contracting that apparatus with its images.

\section{REFERENCES}

1. Research on how to use water dripping from dishes. (Dish racking system patent from google scholar)

2. http://www.blinexindia.com/porous-filtersheets.htm for taking the purpose of building the plastic sheets to purify water.

3. How to use purifying sheets.

4. Research on how to link pipelines for different supplies.

5. Research on how to reuse aqua guard water.

\section{Cite this article as :}

Harsh Jindal, Jagdeep Kaur, "The Instrument to Use Contaminated Water to Save Aqua for Future Generation", International Journal of Scientific Research in Science, Engineering and Technology (IJSRSET), Online ISSN : 2394-4099, Print ISSN : 2395-1990, Volume 8 Issue 2, pp. 359-361, MarchApril 2021. Available at doi : https://doi.org/10.32628/IJSRSET218287 Journal URL : https://ijsrset.com/IJSRSET218287 